Article

\title{
Occurrence and Profiles of the Artificial Endocrine Disruptor Bisphenol A and Natural Endocrine Disruptor Phytoestrogens in Urine from Children in China
}

\author{
Mingyue Zhang ${ }^{1,+}$, Zhenghua Duan ${ }^{2,3,+}$, Yinghong $\mathrm{Wu}^{1}$, Zhen Liu ${ }^{2}$, Ke Li ${ }^{2}$ and Lei Wang ${ }^{2, *}$ \\ Received: 17 October 2015; Accepted: 20 November 2015; Published: 30 November 2015 \\ Academic Editor: Huixiao Hong \\ 1 Tianjin Centers for Disease Control and Prevention, Tianjin 300171, China; cdczhangmy@126.com (M.Z.); \\ wuyinghongnk@126.com (Y.W.) \\ 2 Ministry of Education Key Laboratory of Pollution Processes and Environmental Criteria/Tianjin Key \\ Laboratory of Environmental Remediation and Pollution Control, Nankai University, \\ Tianjin 300071, China; duanzhenghua@mail.nankai.edu.cn (Z.D.); m15822267505@163.com (Z.L.); \\ like1030@mail.nankai.edu.cn (K.L.) \\ 3 School of Environmental Science and Safety Engineering, Tianjin University of Technology, \\ Tianjin 300384, China \\ * Correspondence: wang2007@nankai.edu.cn; Tel.: +86-22-2350-9241 \\ + These authors contributed equally to this work.
}

\begin{abstract}
Background: Exposure to artificial or natural endocrine disruptors, such as bisphenol A (BPA) and phytoestrogens has been demonstrated to have health effects, especially in children. Biomonitoring of BPA and phytoestrogens in human urine can be used to assess the intake levels of these compounds. Methods: In this study, BPA and phytoestrogens in urine specimens $(n=256)$ collected from children in China were measured by liquid chromatography (LC)-tandem mass spectrometry (MS/MS). Results: BPA was detected in most specimens, with a geometric mean concentration of $1.58 \mathrm{ng} / \mathrm{mL}$. For the first time, levels of urinary phytoestrogens in Chinese children were reported. Daidzein and enterolactone are the typical isoflavones and lignans compounds in urine, respectively. Conclusions: Relatively high levels of urinary BPA indicate an increasing risk of BPA exposure to Chinese children. Urinary concentrations of daidzein in Chinese children are higher when compared with those reported in the U.S. children, while concentrations of urinary enterolactone and enterodiols are significantly lower. This suggests a significant difference in phytoestrogen intake between the children from China and from the U.S.
\end{abstract}

Keywords: bisphenol A; phytoestrogens; biomonitoring; children; China

\section{Introduction}

Exposure of exogenous chemicals can affect human health, which has resulted in an urgent need for human biomonitoring. For example, the Fourth National Report on Human Exposure to Environmental Chemicals, a national biomonitoring program in the U.S., mentions more than two hundred detected chemicals [1].

As an artificial chemical, 2,2-bis[4-hydroxyphenyl] propane (bisphenol A, BPA) is commonly used in the manufacturing of polycarbonate plastics and epoxy resins. BPA is of concern because it has been identified as an endocrine disrupting chemical (EDC) [2], implicated in reproductive and developmental anomalies in laboratory animals [3,4], and linked to a variety of adverse human health 
outcomes $[5,6]$. Biomonitoring studies have indicated a wide occurrence of detectable urinary BPA levels in humans from several countries [1,7-14].

Phytoestrogens are naturally occurring polycyclic phenols found in certain plants. Although numerous epidemiological and clinical studies have tried to evaluate the relationship between phytoestrogen consumption and human disease outcomes, the therapeutic potential of these compounds remains unclear [15]. On the contrary, these chemicals may have weak estrogenic effects when they are ingested and metabolized. The endocrine disrupting properties of phytoestrogens have been proposed in animals and in some epidemiological studies [15-17]. Isoflavones and lignans are two important groups of phytoestrogens. Two typical lignin urinary metabolites, i.e., enterodiol and enterolactone, and four typical isoflavone urinary metabolites, i.e., daidzein, genistein, equol, and $O$-desmethyl-angolensin (O-DMA), have been included in the U.S. national biomonitoring program [1]. However, knowledge about the occurrence of urinary phytoestrogens in the Chinese population is still insufficient, especially in Chinese children. Urine specimens are a common matrix for the biomonitoring of human exposure to chemicals.

In the current study, 256 urine samples from children in Tianjin, China were collected, and the concentrations of BPA and six phytoestrogens compounds were determined using liquid chromatography (LC)-tandem mass spectrometry (MS/MS). Urinary concentrations of BPA and phytoestrogens are highly correlated with dietary intakes, and hence are valuable in assessing human exposure to these compounds.

\section{Materials and Methods}

\subsection{Sample Collection}

Tianjin is the fourth largest city in China, and also the industrial center and largest coastal city in Northern China. Urine specimens in this study come from a health and nutrition examination survey biomonitoring program of Tianjin Municipal Health Bureau. Probability proportion to size sampling was applied to collect urine specimens. In detail, during April and May 2014, 24 primary schools were randomly selected from the total of 956 schools in Tianjin. From each school, 11 students aged 8-10 years, were randomly invited to participate in urine specimen collection, after obtaining the consent of the children and their parents. All urine samples were collected in polypropylene (PP) tubes and shipped in dry ice to the laboratory within $6 \mathrm{~h}$. In the laboratory, samples were stored at $-80^{\circ} \mathrm{C}$ before analysis. After excluding the losses during transportation and storage, urine samples $(n=256)$ from 132 boys and 124 girls, were measured for BPA and six phytoestrogens in the laboratory, with approval from the Ethics Committee of Nankai University.

\subsection{Chemicals}

Analytical standards of BPA ( $\geqslant 97 \%)$, enterolactone $(95 \%)$, enterodiol $(95 \%)$, daidzein $(98 \%)$, equol (99\%), genistein (98\%), creatinine $(99 \%)$ and $\beta$-glucuronidase $(145700$ units $/ \mathrm{mL}$ $\beta$-glucuronidase and 887 units $/ \mathrm{mL}$ sulfatase) were purchased from Sigma-Aldrich (St. Louis, MO, USA). O-DMA (98\%) was purchased from Plantech (Reading, UK). Stable isotope-labeled standards, ${ }^{13} \mathrm{C}_{12}$-BPA, $\mathrm{D}_{3}$-daidzein and $\mathrm{D}_{4}$-genistein were purchased from Cambridge Isotope Laboratories (Andover, MA, USA). D 3 -creatinine (99\%) was purchased from CDN Isotopes (Pointe-Claire, QC, Canada).

\subsection{Sample Pretreatment}

To determine both the free and conjugated forms of the target analytes, $500 \mu \mathrm{L}$ urine samples were transferred into a $15-\mathrm{mL}$ PP tube, and $300 \mu \mathrm{L}$ of $1.0 \mathrm{M}$ ammonium acetate containing 22 units of $\beta$-glucuronidase, as well as ${ }^{13} \mathrm{C}_{12}$-BPA, $\mathrm{D}_{3}$-daidzein and $\mathrm{D}_{4}$-genistein ( $5 \mathrm{ng}$ of each), was added. After enzymatic deconjugation at $37^{\circ} \mathrm{C}$ overnight, the digested samples were extracted by liquid-liquid extraction (LLE) and analyzed by LC-MS/MS. In brief, a digested sample was extracted twice by 
$4+4 \mathrm{~mL}$ of ethyl acetate, which was conducted with 60 min shaking each time. After centrifugation $(5000 \times g, 5 \mathrm{~min})$, the supernatants of the double LLE were combined and $1 \mathrm{~mL}$ of Milli-Q water was added to wash the extract. After that, extracts were concentrated to near-dryness under a gentle nitrogen stream, and redissolved in $0.5 \mathrm{~mL}$ of methanol for LC-MS/MS analysis.

\subsection{Chemical Analysis}

Analysis of BPA and phytoestrogens was accomplished by an Acquity Ultra Performance LC system (Waters, Milford, MA, USA) interfaced with a Waters TQD tandem quadrupole mass spectrometer operated in the electrospray negative ion mode (ESI ${ }^{-}$-MS/MS). Ten microliters of the sample were injected onto an analytical column (Acquity UPLC BEH C $18,1.7 \mu \mathrm{m}, 100 \times 2.1 \mathrm{~mm}$ ). The mobile phase comprised methanol (A) and Milli-Q water (B). A gradient elution was started from $35 \%$ (A), increased to $90 \%$ (A) at 0-2 $\mathrm{min}$, to $96 \%$ (A) at $2-2.5 \mathrm{~min}$, to $97 \%$ (A) at $2.5-5 \mathrm{~min}$, to $100 \%$ (A) at 5-5.1 min and held for $0.9 \mathrm{~min}$, then decrease to $35 \%$ (A) at 6-8 min and held $2 \mathrm{~min}$ before next injection. The flow rate was $300 \mathrm{~mL} / \mathrm{min}$. The MS/MS was operated in the multiple reaction monitoring (MRM). The MRM transitions monitored for BPA and phytoestrogens were similar to those mentioned in $[18,19]$. An isotope dilution method was used in analyte quantification. $\mathrm{D}_{3}$-daidzein was used for the quantification of enterolactone, enterodiol, equol, and O-DMA, given that no commercial iso-standards were available for these phytoestrogens. The recoveries of all target compounds spiked in matrices ranged from $81.3 \%$ to $113.7 \%$ (corrected by the recoveries of the internal standards). Creatinine was also detected by LC-MS/MS, according to the method described in our previous study [20].

\subsection{Quality Assurance and Quality Control}

For each batch of 20 samples, a procedural blank, a spiked blank, and a pair of matrix-spiked samples were analyzed. Procedural blanks were prepared by substitution of $0.5 \mathrm{~mL}$ of Milli-Q water for urine, followed by passage through the entire analytical procedure, indicating no target analytes detected in procedural blanks. The relative standard deviation (RSD) of replicate analysis of samples was $<10 \%$. The limit of quantification (LOQ) was 0.05 (for BPA), 2.50 (for enterolactone), 0.25 (for enterodiol), 9.00 (for daidzein), 5.00 (for equol), 0.25 (for $O$-DMA), and $1.5 \mathrm{ng} / \mathrm{mL}$ (for genistein), respectively, which was determined based on the lowest acceptable concentration in a calibration standard and a nominal sample volume of $0.5 \mathrm{~mL}$. As a check for instrumental drift in response factors, a midpoint calibration standard was injected after every 10 samples; and a pure solvent (methanol) was injected as a check for cross-over from sample to sample. Instrumental calibration was verified by the injection of a 10-point calibration standard, and the regression coefficient $(r)$ of calibration curves was $\geqslant 0.99$.

\subsection{Data Analysis}

Statistical analyses were performed with SigmaPlot (Systat Software Inc., San Jose, CA, USA). For data analysis, concentrations below the LOQ were assigned a value equal to $L O Q / \sqrt{2}$ in the calculation of geometric mean (GM). Correlations between analytes were examined by Spearman' correlation analysis. One-way analysis of variance was used to assess the differences between groups. A value of $p<0.05$ was considered significant.

\section{Results}

Of the 256 urine specimens analyzed, BPA was found in 254 (99.2\%) of the specimens (Table 1), indicating a widespread human exposure to BPA in the studied child population. The GM concentration of BPA was $1.55 \mathrm{ng} / \mathrm{mL}$ in children's urine of, with GM urinary BPA concentrations of $1.32 \mathrm{ng} / \mathrm{mL}$ in girls and $1.73 \mathrm{ng} / \mathrm{mL}$ in boys, respectively. When adjusted by urinary creatinine, GM concentrations of urinary BPA in girls and boys were calculated to be 2.47 and $2.37 \mu \mathrm{g} / \mathrm{g}$-creatinine, respectively (Table 1). 
Table 1. Occurrence of BPA and phytoestrogens in urine of children from Tianjin, China.

\begin{tabular}{|c|c|c|c|c|c|c|c|c|c|c|c|c|c|c|}
\hline & \multicolumn{7}{|c|}{ Urinary Concentration $(\mathrm{ng} / \mathrm{mL})$} & \multicolumn{7}{|c|}{ Corrected by Urinary Creatinine $(\mu \mathrm{g} / \mathrm{g})^{\mathrm{c}}$} \\
\hline & $\overline{\text { BPA }}$ & Enterolactone & Enterodiol & Daidzein & O-DMA & Genistein & Equol & $\overline{B P A}$ & Enterolactone & Enterodiol & Daidzein & O-DMA & Genistein & Equol \\
\hline \multicolumn{15}{|c|}{ Children $(n=256)$} \\
\hline $\mathrm{GM}^{\mathrm{a}}$ & 1.58 & 162 & 21.4 & 142 & 4.87 & 21.7 & 10.8 & 2.52 & 258 & 34.1 & 226 & 7.76 & 34.6 & 17.2 \\
\hline $\mathrm{AM}^{\mathrm{b}}$ & 2.47 & 407 & 120 & 435 & 33.3 & 64.4 & 44.5 & 1.93 & 948 & 379 & 1350 & 71.6 & 204 & 182 \\
\hline $\operatorname{Max}$ & 24.9 & 2910 & 4250 & 2720 & 346 & 419 & 336 & 74.3 & 258 & 34.1 & 226 & 7.76 & 34.6 & 29.6 \\
\hline $\mathrm{DF} \%$ & 99.2 & 100 & 98.4 & 93.4 & 71.9 & 98.4 & 53.1 & & & & & & & \\
\hline \multicolumn{15}{|c|}{ Girls $(n=124)$} \\
\hline GM & 1.32 & 165 & 18.1 & 101 & 6.48 & 17.6 & 10.1 & 2.47 & 310 & 34.0 & 189 & 12.2 & 33.2 & 19.0 \\
\hline $\mathrm{AM}$ & 1.99 & 366 & 48.8 & 379 & 37.0 & 58.7 & 38.7 & 2.11 & 1010 & 251 & 1320 & 107 & 242 & 70.6 \\
\hline Max & 10.3 & 2910 & 595 & 2720 & 241 & 419 & 319 & 69.4 & 7090 & 4955 & 14,200 & 622 & 2180 & 308 \\
\hline $\mathrm{DF} \%$ & 98.4 & 100 & 100 & 90.3 & 61.3 & 100 & 62.9 & & & & & & & \\
\hline \multicolumn{15}{|c|}{ Boys $(n=132)$} \\
\hline GM & 1.76 & 160 & 25.4 & 200 & 3.66 & 26.8 & 11.6 & 2.37 & 214 & 34.2 & 270 & 4.94 & 36.1 & 15.6 \\
\hline $\mathrm{AM}$ & 2.52 & 449 & 192 & 492 & 29.7 & 70.2 & 50.3 & 1.87 & 888 & 507 & 1380 & 36.2 & 166 & 241 \\
\hline $\operatorname{Max}$ & 24.9 & 2300 & 4250 & 2580 & 346 & 346 & 336 & 74.3 & 12,500 & 9680 & 22,200 & 274 & 1200 & 5770 \\
\hline $\mathrm{DF} \%$ & 100 & 100 & 97.0 & 99.2 & 84.4 & 97.0 & 43.9 & & & & & & & \\
\hline
\end{tabular}

${ }^{a}$ GM: geometric mean, to obtain GM, a value of $L O Q / \sqrt{2}$ was assigned to sample with values $<L O Q ;{ }^{b} \mathrm{AM}$ : arithmetic mean; ${ }^{\mathrm{c}} \mathrm{GM} \pm \mathrm{GSD}$ (geometric standard deviation) of urinary creatinine was measured as $454 \pm 4.01 \mu \mathrm{g} / \mathrm{mL}$. 
High detection frequencies ( $>90 \%$ ) were observed for urinary enterolactone, enterodiol, daidzein, and genistein. O-DMA (in 184 specimens) and equol (in 136 specimens) were also detected in the children's urine (Table 1). Among the six target phytoestrogens, enterolactone and daidzein are the predominant compounds, with GM concentrations of 162 and $142 \mathrm{ng} / \mathrm{mL}$, respectively.

For the urinary enterodiol and genistein, GM concentrations of about $20 \mathrm{ng} / \mathrm{mL}$ was detected. Concentration levels of equol and O-DMA was lower, with GM values of 10.8 and $4.87 \mathrm{ng} / \mathrm{mL}$, respectively. A significant difference was observed for urinary daidzein in Chinese boys and girls. GM concentration of $200 \mathrm{ng} / \mathrm{mL}$ was obtained for urinary daidzein in boys, which is two times that in girls (GM: $101 \mathrm{ng} / \mathrm{mL}$ ).

\section{Discussion}

China is one of the biggest consumers of BPA, with an estimated annual BPA demand of about $3 \times 10^{6}$ tonnes [21]. Biomonitoring studies of BPA in the Chinese population have been reported in recent years [11-14]. For example, He et al. reported a wide occurrence of BPA in human urine collected in 2008 from Shanghai, one of the biggest cities in Eastern China, with GM BPA concentrations of $0.31 \mathrm{ng} / \mathrm{mL}$ in children aged 8-11 years [11]. Another investigation in 2012 also indicated a GM concentration of $0.45 \mathrm{ng} / \mathrm{mL}$ in school children from Shanghai [12]. More recently, Wang et al. reported a GM concentration of $1.11 \mathrm{ng} / \mathrm{mL}$ for urinary BPA in children from Shanghai [13]. However, the existing studies mainly focus on the population in Eastern and Southern China, and little data is available for estimating the exposure to BPA of people living in Northern China. In the current study, the GM concentration of urinary BPA was measured to be $1.55 \mathrm{ng} / \mathrm{mL}$ in children from Tianjin in Northern China. Compared with the previous Chinese children data, an increasing trend of BPA exposure in Chinese children might exist (Figure 1), when ignoring the regional differences between Shanghai and Tianjin. However, all the available data come from some small size biomonitoring studies [11-13] and a continuous systematic survey is still required to confirm the BPA exposure trend.

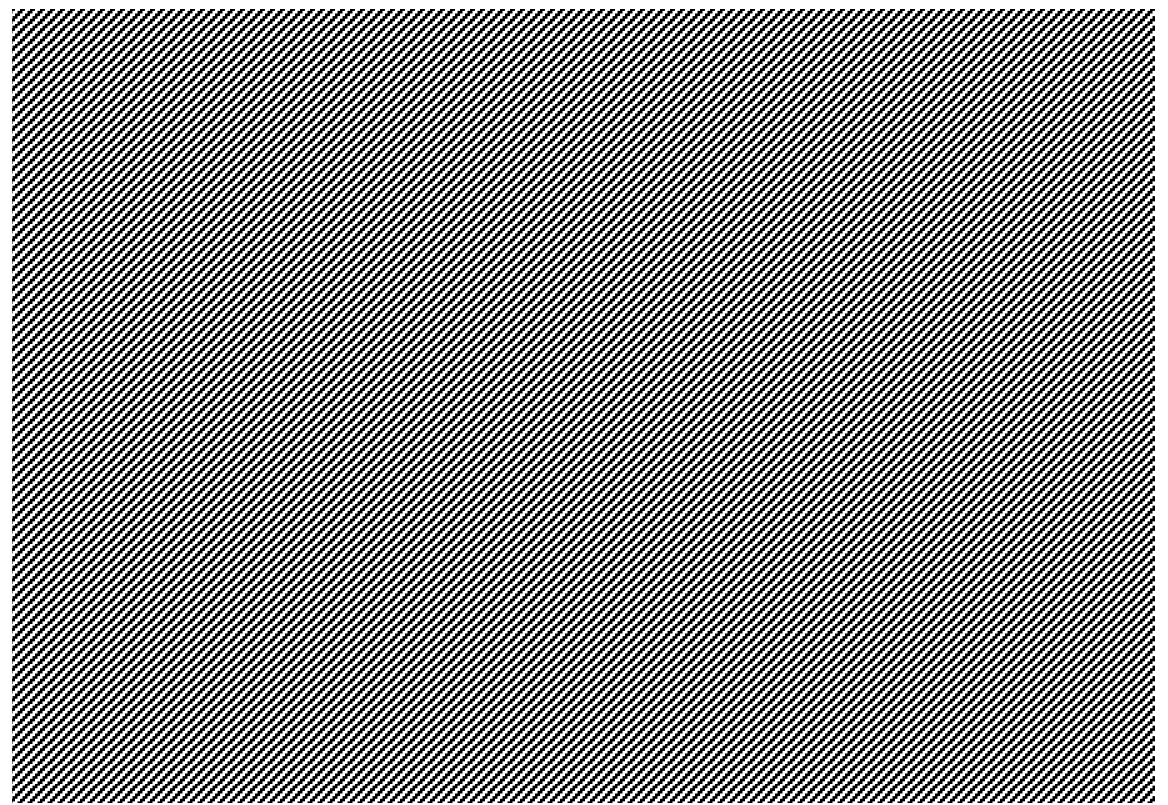

Figure 1. Chronological changes of GM concentration urinary BPA in children from China; the data comes from references [11-13] and the results of the current study.

Concentrations of urinary BPA have been reported by the U.S. Centers for Disease Control and Prevention (USCDC) in their Fourth National Report on Human Exposure to Environmental Chemical [1]. In the newest updated table, BPA was reported to be detected in almost all urine 
samples taken the U.S., with a GM concentration of $1.51 \mathrm{ng} / \mathrm{mL}$ (in the 2011-2012 survey) [1]. This suggests that the BPA exposure of the Chinese children in this study might be at a similar level as that present in U.S. children.

Two typical isoflavone metabolites, daidzein and genistein, were widely detected in urine from Chinese children in this study. In addition, metabolites of daidzein, i.e., O-DMA and equol, were also detected in a part of the urine specimens. Knowledge about urinary phytoestrogen levels in Chinese is limited [22-24]. In Chinese pregnant women, GM concentrations of urinary daidzein, enterolactone and enterodiol were detected to be $115,56.2$, and $24.1 \mu \mathrm{g} / \mathrm{g}$-creatinine, respectively [22]. In addition, GM concentrations of urinary phytoestrogens, i.e., $46.6 \mathrm{\mu g} / \mathrm{g}$-creatinine for daidzein, $36.6 \mu \mathrm{g} / \mathrm{g}$-creatinine for genistein, and $5.55 \mu \mathrm{g} / \mathrm{g}$-creatinine for equol, were reported in Chinese men [23]. These results suggest significantly lower urinary levels of phytoestrogens in Chinese adults than in children. Similar differences between children and adults can also be observed in the U.S. [1]. Besides, a significant gender difference was observed only for urinary daidzein $(p<0.01)$.

According to the data from the U.S. National Health and Nutrition Examination Survey [1], the urinary concentrations of enterolactone (GM: $255 \mathrm{ng} / \mathrm{mL}$ ) and genistein (GM: $46.1 \mathrm{ng} / \mathrm{mL}$ ) in 6-11 years children from the U.S. were significantly higher than those detected in Chinese children $(p<0.05)$. On the contrary, concentration of urinary daidzein in the U.S. children (GM: $109 \mathrm{ng} / \mathrm{mL})$ is lower than that in Chinese children (Figure 2).

Significant correlations were found between the homologous phytoestrogens, e.g., enterolactone and enterodiol $(R=0.530, p=0.000)$, daidzein and genistein $(R=0.744, p=0.000)$, daidzein and equol $(R=0.608, p=0.000$ ), (Table 2 ). However, no obvious correlation was found between BPA and phytoestrogens.

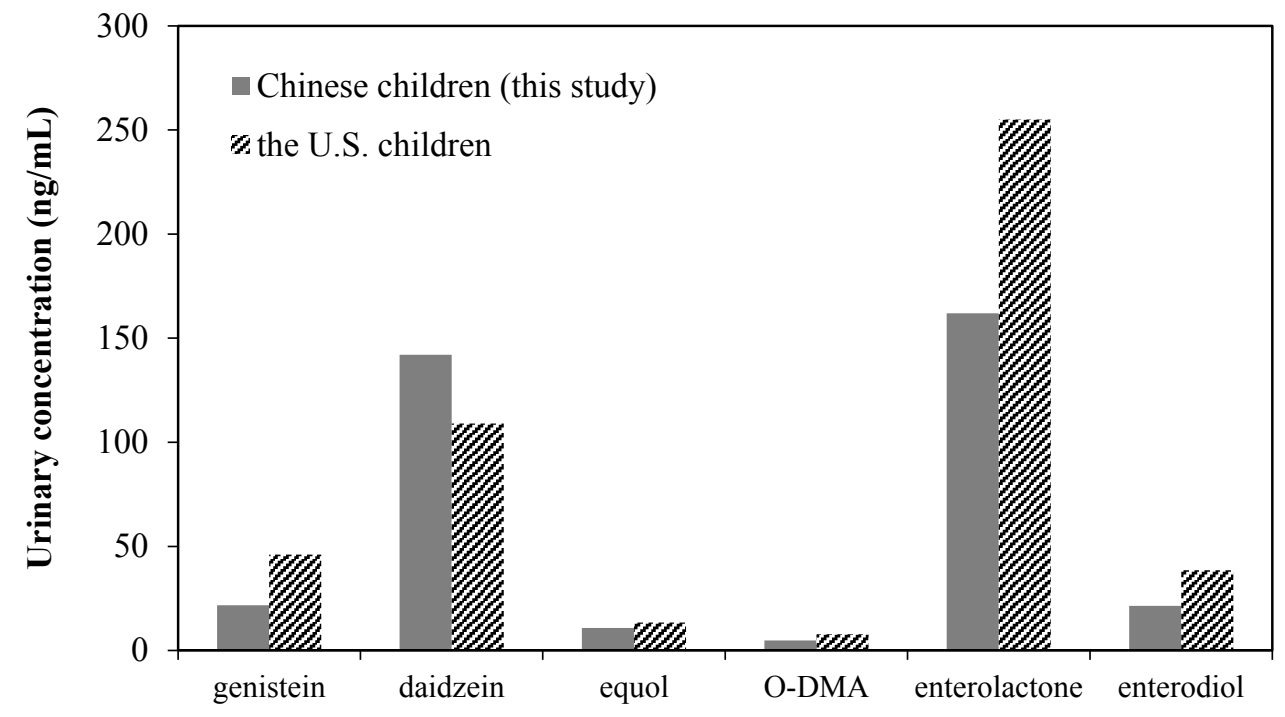

Figure 2. GM concentration of urinary phytoestrogens in children from China and the U.S. U.S. data from reference [1].

Table 2. Results of Spearman's correlation analysis between analytes.

\begin{tabular}{ccccccccccccc}
\hline & \multicolumn{2}{c}{ BPA } & \multicolumn{2}{c}{ Enterodiol } & \multicolumn{2}{c}{ Daidzein } & \multicolumn{2}{c}{ O-DMA } & \multicolumn{2}{c}{ Genistein } & \multicolumn{2}{c}{ Equol } \\
\hline & \multicolumn{1}{c}{$\boldsymbol{R}$} & $\boldsymbol{p}$ & $\boldsymbol{R}$ & $\boldsymbol{p}$ & $\boldsymbol{R}$ & $\boldsymbol{p}$ & $\boldsymbol{R}$ & $\boldsymbol{p}$ & $\boldsymbol{R}$ & $\boldsymbol{p}$ & $\boldsymbol{R}$ & $\boldsymbol{p}$ \\
\hline enterolactone & 0.224 & 0.088 & 0.530 & 0.000 & 0.097 & 0.481 & 0.230 & 0.142 & -0.010 & 0.940 & 0.462 & 0.008 \\
enterodiol & 0.073 & 0.583 & & & 0.324 & 0.016 & 0.326 & 0.033 & 0.251 & 0.057 & 0.142 & 0.448 \\
daidzein & 0.301 & 0.024 & & & & & 0.338 & 0.031 & 0.744 & 0.000 & 0.608 & 0.000 \\
O-DMA & -0.037 & 0.815 & & & & & & & 0.095 & 0.544 & 0.222 & 0.376 \\
genistein & 0.193 & 0.143 & & & & & & & & & 0.321 & 0.079 \\
equol & 0.407 & 0.021 & & & & & & & & & & \\
\hline
\end{tabular}




\section{Conclusions}

In this study BPA was widely detected in urine from children in Tianjin, China, at a concentration level higher than that reported for Chinese children in the past. The relatively high urinary BPA concentration level in this study indicates an increasing risk of BPA exposure to Chinese children. In addition, attention should be paid to the human exposure to BPA substitutes, such as bisphenol S (BPS), bisphenol F (BPF), and bisphenol B (BPB). While intake of phytoestrogens has been frequently associated with health benefits, potentially adverse effects on development, reproductive and endocrine systems are being observed [25]. Levels of urinary phytoestrogens in Chinese children are lower than the reported levels in Chinese adults. In addition, compared with the concentration levels in the U.S. children, significantly higher urinary daidzein levels were observed in the Chinese children, especially in Chinese boys, that should be of concern.

Acknowledgments: The authors disclosed receipt of the following financial support for the research, authorship, and/or publication of this article: National Natural Science Foundation of China (No. $41225014 \& 21177065$ ) and Science and Technology Foundation of Tianjin Municipal Health Bureau (2013KY21).

Author Contributions: Lei Wang was responsible for the study concept, study design and critical revision of the manuscript for important scientific content. Mingyue Zhang and Zhenghua Duan were responsible for data interpretation and manuscript drafting. Yinghong $\mathrm{Wu}$ was responsible for data analysis. Zhen Liu and $\mathrm{Ke} \mathrm{Li}$ were responsible for laboratory testing.

Conflicts of Interest: The authors declare no conflict of interest.

\section{References}

1. USCDC (the U.S. Centers for Disease Control and Prevention). Fourth National Report on Human Exposure to Environmental Chemicals Updated Tables; USCDC: Clifton Road Atlanta, GA, USA, 2015. Available online: http://www.cdc.gov/biomonitoring/pdf/FourthReport_UpdatedTables_Feb2015.pdf (accessed on 10 October 2015).

2. Vom Saal, F.S.; Cooke, P.S.; Buchanan, D.L.; Palanza, P.; Thayer, K.A.; Nagel, S.C.; Parmigiani, S.; Welshons, W.V. A physiologically based approach to the study of bisphenol A and other estrogenic chemicals on the size of reproductive organs, daily sperm production, and behavior. Toxicol. Ind. Health 1998, 14, 239-260. [CrossRef] [PubMed]

3. Vom Saal, F.S.; Richter, C.A.; Ruhlen, R.R.; Nagel, S.C.; Timms, B.G.; Welshons, W.V. The importance of appropriate controls, animal feed, and animal models in interpreting results from low-dose studies of bisphenol A. Birth Defects. Res. Part A 2005, 73, 140-145. [CrossRef] [PubMed]

4. Vom Saal, F.S.; Welshons, W.V. Large effects from small exposures. II. The importance of positive controls in low-dose research on bisphenol A. Environ. Res. 2006, 100, 50-76. [CrossRef] [PubMed]

5. Hengstler, J.G.; Foth, H.; Gebel, T.; Kramer, P.J.; Lilienblum, W.; Schweinfurth, H.; Völkel, W.; Wollin, K.M.; Gundert-Remy, U. Critical evaluation of key evidence on the human health hazards of exposure to bisphenol A. Crit. Rev. Toxicol. 2011, 41, 263-291. [CrossRef] [PubMed]

6. Goodman, J.E.; Witorsch, R.J.; McConnell, E.E.; Sipes, I.G.; Slayton, T.M.; Yu, C.J.; Franz, A.M.; Rhomberg, L.R. Weight-of-evidence evaluation of reproductive and developmental effects of low doses of bisphenol A. Crit. Rev. Toxicol. 2009, 39, 1-75. [CrossRef] [PubMed]

7. Calafat, A. Background Paper on BPA Biomonitoring and Biomarkerstudies; World Health Organization: Geneva, Switzerland, 2011. Available online: http://www.who.int/foodsafety/chem/chemicals/ 6.1_bpa_biomonitoring_and_biomarker_studies.pdf (accessed on 10 October 2015).

8. Vandenberg, L.N.; Chahoud, I.; Heindel, J.J.; Padmanabhan, V.; Paumgartten, F.J.R.; Schoenfelder, G. Urinary, circulating, and tissue biomonitoring studies indicate widespread exposure to bisphenol A. Environ. Health Perspect. 2010, 118, 1055-1070. [CrossRef] [PubMed]

9. Bushnik, T.; Haines, D.; Levallois, P.; Levesque, J.; Van Oostdam, J.; Viau, C. Lead and bisphenol A concentrations in the Canadian population. Health Rep. 2010, 21, 7-18. [PubMed]

10. Kim, Y.H.; Kim, C.S.; Park, S.; Han, S.Y.; Pyo, M.Y.; Yang, M. Gender differences in the levels of bisphenol A metabolites in urine. Biochem. Biophys. Res. Commun. 2003, 312, 441-448. [CrossRef] [PubMed] 
11. He, Y.; Miao, M.; Herrinton, L.J.; Wu, C.; Yuan, W.; Zhou, Z.; Li, D.K. Bisphenol A levels in blood and urine in a Chinese population and the personal factors affecting the levels. Environ. Res. 2009, 109, 629-633. [CrossRef] [PubMed]

12. Wang, H.; Zhou, Y.; Tang, C.; Wu, J.; Chen, Y.; Jiang, Q. Association between bisphenol A exposure and body mass index in Chinese school children: A cross-sectional study. Environ. Health 2012, 11. [CrossRef] [PubMed]

13. Wang, B.; Wang, H.; Zhou, W.; He, Y.; Zhou, Y.; Chen, Y.; Jiang, Q. Exposure to bisphenol A among school children in eastern China: A multicenter cross-sectional study. J. Expo. Sci. Environ. Epidemiol. 2014, 24. [CrossRef] [PubMed]

14. Zhang, Z.; Alomirah, H.; Cho, H.S.; Li, Y.F.; Liao, C.; Minh, T.B.; Mohd, M.A.; Nakata, H.; Ren, N.; Kannan, K. Urinary bisphenol A concentrations and their implications for human exposure in several Asian countries. Environ. Sci. Technol. 2011, 45, 7044-7050. [CrossRef] [PubMed]

15. Patisaul, H.B.; Jefferson, W. The pros and cons of phytoestrogens. Front. Neuroendocrinol. 2010, 31, 400-419. [CrossRef] [PubMed]

16. Hooper, L.; Ryder, J.J.; Kurzer, M.S.; Lampe, J.W.; Messina, M.J.; Phipps, W.R.; Cassidy, A. Effects of soy protein and isoflavones on circulating hormone concentrations in pre- and post-menopausal women: A systematic review and meta-analysis. Hum. Reprod. Update 2009, 15, 423-440. [CrossRef] [PubMed]

17. Patisaul, H.B.; Luskin, J.R.; Wilson, M.E. A soy supplement and tamoxifen inhibit sexual behavior in female rats. Hormones Behav. 2004, 45, 270-277. [CrossRef] [PubMed]

18. Wang, L.; Asimakopoulos, A.G.; Kannan, K. Accumulation of 19 environmental phenolic and xenobiotic heterocyclic aromatic compounds in human adipose tissue. Environ. Int. 2015, 78, 45-50. [CrossRef] [PubMed]

19. Kunisue, T.; Tanabe, S.; Isobe, T.; Aldous, K.M.; Kannan, K. Profiles of phytoestrogens in human urine from several Asian countries. J. Agric. Food Chem. 2010, 58, 9838-9846. [CrossRef] [PubMed]

20. Wang, L.; Wu, Y.; Zhang, W.; Kannan, K. Widespread occurrence and distribution of bisphenol A diglycidyl ether (BADGE) and its derivatives in human urine from the United States and China. Environ. Sci. Technol. 2012, 46, 12968-12976. [CrossRef] [PubMed]

21. Huang, Y.Q.; Wong, C.K.; Zheng, J.S.; Bouwman, H.; Barra, R.; Wahlström, B.; Neretin, L.; Wong, M.H. Bisphenol A (BPA) in China: A review of sources, environmental levels, and potential human health impacts. Environ. Int. 2002, 42, 91-99. [CrossRef] [PubMed]

22. Tang, R. Association of Prenatal Phytoestrogen Exposures and Maternal Estrogen Metabolite Levels with Birth Outcomes. Master thesis, Nanjing Medical University, Nanjing, China, 2013. (In Chinese).

23. Xia, Y.K.; Chen, M.J.; Zhu, P.F.; Lu, C.C.; Fu, G.B.; Zhou, X.J.; Chen, D.Z.; Wang, H.H.; Hang, B.; Wang, S.L.; et al. Urinary phytoestrogen levels related to idiopathic male infertility in Chinese men. Environ. Int. 2013, 59, 161-167. [CrossRef] [PubMed]

24. Wu, X.Y.; Cai, H.; Gao, Y.T.; Dai, Q.; Li, H.L.; Cai, Q.Y.; Yang, G.; Franke, A.A.; Zheng, W.; $\mathrm{Shu}$, X.O. Correlations of urinary phytoestrogen excretion with lifestyle factors and dietary intakes among middle-aged and elderly Chinese women. Int. J. Mol. Epidemiol. Genet. 2012, 3, 18-29. [PubMed]

25. Cederroth, C.R.; Zimmermann, C.; Nef, S. Soy, phytoestrogens and their impact on reproductive health. Mol. Cell. Endocrinol. 2012, 355, 192-200. [CrossRef] [PubMed]

(C) 2015 by the authors; licensee MDPI, Basel, Switzerland. This article is an open access article distributed under the terms and conditions of the Creative Commons by Attribution (CC-BY) license (http:// creativecommons.org/licenses/by/4.0/). 